\title{
Significant Variation Exists Among Laboratories Measuring Onion Bulb Quality Traits
}

\author{
Michael J. Havey ${ }^{1}$ \\ Vegetable Crops Unit, Agricultural Research Service, U.S. Department of \\ Agriculture, Department of Horticulture, 1575 Linden Drive, University of \\ Wisconsin, Madison, WI 53706
}

Marita Cantwell

Department of Vegetable Crops, University of California, Davis, CA 95616

Meriel G. Jones

Plant Science and Fungal Molecular Biology Research Group, School of Biological Sciences, Donnan Laboratories, The University of Liverpool, Crown Street, Liverpool L69 7ZD, United Kingdom

Richard W. Jones

Seminis Vegetable Seeds, 1500 Research Parkway, Suite A120, College Station, TX 77845

Norman E. Schmidt

Department of Chemistry, P.O. Box 8064, Georgia Southern University, Statesboro, GA 30460

John Uhlig

Seminis Vegetable Seeds, 37437 State Highway 16, Woodland, CA 95695

J.F. Watson

Sunseeds, 8850 59th Avenue N.E., Brooks, OR 97305

\section{Kil Sun Yoo}

Vegetable Improvement Center, Texas A\&M University, College Station, TX 77843

Additional index words. Allium cepa, pungency, soluble solids

Abstract. Onion pungency is a major quality attribute with many consumers demanding less pungent onions. In recent years, some growers and retailers have attempted to measure pungency of onions produced in different regions to guarantee a desired level of pungency. However, there are few data on the variability among laboratories using standardized protocols to estimate relative levels of pungencies. Onion cultivars were grown in replicated trials at three locations. Random samples of bulbs from each experimental unit were harvested and shipped to at least three cooperating laboratories, each of which measured soluble solids content (SSC) and pungencies using the same techniques. As expected, cultivars and environments showed significant $(P<0.001)$ differences. For all three trials, laboratories were a highly significant source of variation $(P<0.024$ to 0.001$)$ for measurements of SSC and pungency. Therefore, one cannot make recommendations on relative pungencies of the same lots of onions measured by different labs. The onion research community must identify specific procedures to reduce variation among laboratories to develop a more repeatable standardized assay for the measurement of onion pungency.

Received for publication 8 Jan. 2002. Accepted for publication 2 July 2002. Names are necessary to report factually on available data; however, the U.S. Dept. of Agriculture (USDA) neither guarantees nor warrants the standard of the product, and the use of the name by USDA implies no approval of the product to the exclusion of others that may also be suitable. All authors contributed equally to this work. The technical help of Mark Petrashek(USDA), Matthew Turner (Georgia State Univ.), and Xunli Nie (UC-Davis) is gratefully acknowledged.

${ }^{1}$ USDA Research Geneticist and Professor of Horticulture. To whom reprint requests should be addressed.
Pungency is one of the most economically important characteristics of onion (Allium cepa L.), with less pungent onions becoming more popular. Schwimmer and Weston (1961) developed an assay to measure onion pungency based on the production of enzymatically derived pyruvate after onion bulb tissue is crushed or juiced. Pyruvate concentrations correlate positively with perceived onion pungencies (Schwimmer and Guadagni, 1962; Wall and Corgan, 1992), as well as with total solids and soluble solids content (SSC) (Bedford, 1984; Galmarini et al., 2001; Lin et al., 1995; Simon,
1995). Even though new procedures or modifications to the Schwimmer and Weston (1961) protocol have been published in an attempt to improve or streamline pungency evaluations (Boyhan et al., 1999; Randle and Bussard, 1993; Thomas et al., 1992; Yoo et al., 1995), the standard technique used to measure onion pungency remains the Schwimmer and Weston (1961) protocol.

Standardization of protocols and confidence in measurements become more important as the popularity of low-pungency onion increases. At present, there are no data on the variation for onion pyruvate concentrations measured using a standard protocol. A group of scientists attending the 1998 National Onion Research Conference felt that it was important to assess the repeatability and variation among evaluations for pyruvate concentrations from different laboratories. We decided to cooperatively measure two bulb quality attributes (SSC and pyruvate concentration) to test the hypothesis that there exists negligible variation among laboratories using standardized techniques.

\section{Materials and Methods}

Onion cultivars were grown in field plots with three replications at locations where each cultivar was adapted. In Summer 2000, 'SXO1429' and 'Tesoro' (SunSeeds) were grown at Brooks, Oregon, and Parma, Idaho; 'Barrage' and 'Sweet Sandwich' (Seminis Seed Company) were grown at Palmyra and Randolph, Wis. In Fall 2000, 'Ebano' and 'Texas Legend' (Seminis Seed Co.) were planted during the third week of September and again during the second week of October in Lower Rio Grande Valley of Texas. Bulb production was under field conditions using standard horticultural practices. Bulbs were harvested when mature and at least 12 bulbs from each replication were shipped in Nov. 2000 (Oregon-Idaho and Wisconsin trials) and June 2001 (Texas trial) by overnight express to each of the participating laboratories. The experimental unit consisted of a random sample of 10 bulbs from each replication of each cultivar (Randle, 1992).

Bulbs were cut into quarters from top to bottom and outer dry scales removed. The quarters of 10 bulbs were weighed together, combined with an equal volume (gram weight to $\mathrm{mL}$ volume) of water, and blended in a commercial blender or juiced by passage through a commercial juicer. The onion juice was used to measure SSC by refractometry (Mann and Hoyle, 1945) and corrected for the 2 -fold dilution. Pyruvate evaluations were completed on the diluted juice according to Schwimmer and Weston (1961). At least three laboratories completed analyses on the 2000 summer trials and five laboratories on the 2001 Texas trial. SSC (percent total dissolved solids) and pyruvate concentrations (mmoles of pyruvate per gram fresh weight) were measured for each replication and data from each laboratory were sent to the senior author for analyses. Environments (locations or planting dates), laboratories, and cultivars were all con- 
Table 1. Least square means \pm standard errors for laboratories measuring soluble solids content and pyruvate concentrations using bulbs from onion cultivars grown in replicated trials in Idaho-Oregon, Wisconsin, and Texas.

\begin{tabular}{|c|c|c|c|c|c|c|c|c|c|c|c|c|}
\hline \multirow[b]{3}{*}{ Lab } & \multicolumn{6}{|c|}{ Soluble solids content ${ }^{2}$} & \multicolumn{6}{|c|}{ Pyruvate $^{y}$} \\
\hline & \multicolumn{2}{|c|}{ Idaho-Oregon } & \multicolumn{2}{|c|}{ Wisconsin } & \multicolumn{2}{|c|}{ Texas } & \multicolumn{2}{|c|}{ Idaho-Oregon } & \multicolumn{2}{|c|}{ Wisconsin } & \multicolumn{2}{|c|}{ Texas } \\
\hline & $\mathrm{SX}^{\mathrm{x}}$ & TS & BA & SS & EB & $\mathrm{TL}$ & SX & TS & BA & SS & EB & $\mathrm{TL}$ \\
\hline 1 & $9.0 \pm 0.3$ & $10.9 \pm 0.3$ & $8.0 \pm 0.2$ & $9.3 \pm 0.2$ & $7.4 \pm 0.2$ & $7.6 \pm 0.2$ & $8.3 \pm 0.4$ & $10.2 \pm 0.4$ & $8.6 \pm 0.4$ & $7.5 \pm 0.4$ & $4.1 \pm 0.3$ & $4.4 \pm 0.3$ \\
\hline 3 & $10.9 \pm 0.3$ & $11.3 \pm 0.4$ & $9.0 \pm 0.2$ & $10.5 \pm 0.2$ & $7.7 \pm 0.2$ & $8.1 \pm 0.2$ & $6.9 \pm 0.4$ & $7.5 \pm 0.4$ & $8.5 \pm 0.4$ & $7.8 \pm 0.4$ & $6.2 \pm 0.3$ & $6.3 \pm 0.3$ \\
\hline 4 & & & & & $7.2 \pm 0.2$ & $7.4 \pm 0.2$ & & & & & $5.3 \pm 0.3$ & $5.4 \pm 0.3$ \\
\hline 5 & & & & & $7.1 \pm 0.2$ & $7.0 \pm 0.2$ & $6.7 \pm 0.4$ & $8.1 \pm 0.4$ & & & $3.6 \pm 0.3$ & $3.7 \pm 0.3$ \\
\hline
\end{tabular}

${ }^{2}$ Percent total dissolved solids of onion juice.

${ }^{y}$ Micromoles pyruvate per gram fresh weight

'Cultivars are 'SXO1429' (SX), 'Tesoro' (TS), 'Barrage' (BA), 'Sweet Sandwich' (SS), 'Ebano' (EB), and 'Texas Legend' (TL).

sidered as random. Analyses of variance (ANOVA) and least square means were calculated using Proc Mix procedure of SAS (SAS Institute, Cary, N.C.). Because of local adaptation and daylength responses (Magruder and Allard, 1937), all cultivars could not be grown at all locations and three separate analyses were completed for the Idaho-Oregon (IDOR), Wisconsin (WI), and Texas (TX) trials.

\section{Results and Discussion}

The analyses of variance for SSC and pungencies for the ID-OR, WI, and TX trials revealed low coefficients of variation $(\approx 6 \%)$, indicating a good experiment. There were significant differences for SSC among cultivars $(P<0.001)$ and environments $(P<0.001)$ in the ID-OR and WI trials (Table 1). No differences among cultivars or environments for SSC were revealed in the TX trial. The cultivar $\times$ environment interaction was significant for SCC $(P<0.042)$ for the ID-OR trail. For all three trials, laboratories were a highly significant $(P<0.001)$ source of variation (Table 1), revealing that refractometry measurements were not consistent among laboratories.

Laboratories represented by far the largest source of variation for pyruvate concentrations $(P=0.024$ to $<0.001)$ across all trials (Table 1). The cultivar $\times$ environment interaction was significant $(P<0.071)$ for pyruvate concentrations. The laboratory $\times$ cultivar interaction for pyruvate concentrations was significant $(P<0.023)$ in the TX trial, indicating that groups did not consistently measure pyruvate concentrations across cultivars. Bulbs possessing less than 5.0 mmoles of enzymatically derived pyruvate per $\mathrm{ml}$ fresh weight are often classified by the onion industry as "sweet". The results of the TX trial revealed that two labs (1 and 5) would have labeled onions from cultivars 'Ebano' and 'Texas Legend' as "sweet", while labs 2, 3, and 4 would have classified the same lots of onions outside of this "sweet" category (Table 1). This study clearly demonstrates that one cannot make recommendations on relative pungencies, as estimated by enzymatically derived pyruvate concentrations, of the same lots of onions measured by different laboratories. This may not be due to inherent variability in the Schwimmer and Weston (1961) protocol, but variation among laboratories due to people, chemicals, etc. Another significant source of variation could be differences in the methods used to juice or blend the onion samples. It is unlikely that significant variation was due to sampling errors associated with 10 randomly selected onion bulbs, because of the low coefficients of variability for all measured traits. Based on these results, the onion research community must identify specific procedures within the Schwimmer and Weston (1961) protocol to reduce variation among laboratories or develop a more repeatable standardized assay for the measurement of onion pyruvate.

\section{Literature Cited}

Bedford, L. 1984. Dry matter and pungency tests on British grown onions. J. Natl. Inst. Agr. Bot. (UK) 16:58-61

Boyhan, G.E., N.E. Schmidt, F.M. Woods, D.G. Himelrick, and W.M. Randle. 1999. Adaption of a spectrophotometric assay for pungency in onion to a microplate reader. J. Food. Qual. 22:225-233.

Galmarini, C.R., I.L. Goldman, and M.J. Havey.
2001. Genetic analyses of correlated solids, flavor, and health-enhancing traits in onion (Allium cepa L.). Mol. Gen. Genomics 265:543-551.

Lin, M., J.F. Watson, and J.R. Baggett. 1995. Inheritance of soluble solids and pyruvic acid content of bulb onions. J. Amer. Soc. Hort. Sci. 120:119122.

Magruder, R.H. and R.W. Allard. 1937. Bulb formation in some American and European varieties of onions as affected by length of day. J. Agr. Res. 54:719-752.

Mann, L. and B. Hoyle. 1945. Use of refractometer for selecting onion bulbs high in dry matter for breeding. J. Amer. Soc. Hort. Sci. 46:285-289.

McCollum, G. 1968. Heritability and genetic correlations of soluble solids, bulb size and shape in white sweet Spanish onion. Can. J. Genet. Cytol. 10:508-514.

Randle, W.M. 1992. Sampling procedures to estimate flavor potential in onion. HortScience 27:1116-17.

Randle, W.M. and M.L. Bussard. 1993. Streamlining onion pungency analyses. HortScience 28:60.

Schwimmer, S. and D.G. Guadagni. 1962. Relation between olfactory threshold concentration and pyruvic acid content of onion juice. J. Food Sci. 27:94-97.

Schwimmer, S. and W. Weston. 1961. Enzymatic development of pyruvic acid in onion as a measure of pungency. J. Agr. Food Chem. 9:301304

Simon, P.W. 1995. Genetic analysis of pungency and soluble solids in long-storage onions. Euphytica 82:1-8.

Thomas, D.J., K.L. Parkin, and P.W. Simon. 1992. Development of a simple pungency indicator test for onions. J. Sci. Food Agr. 60:499-504.

Wall, M.M. and J.N. Corgan. 1992. Relationship between pyruvate analysis and flavor perception for onion pungency determination. HortScience 27:1029-1030.

Yoo, K.S., L.M. Pike, and B.K. Hamilton. 1995. A simplified pyruvic acid analysis suitable for onion breeding programs. HortScience 30:1306. 